\title{
Bilirubin Excretion in Rats with Normal and Impaired Bilirubin Conjugation: Effect of Phenobarbital
}

\author{
Stephen H. Robinson, Claudine Yannoni, and Susumu Nagasawa \\ From the Department of Medicine, Beth Israel Hospital and Harvard Medical \\ School, Boston, Massachusetts 02215
}

A B S T R A C T The effect of phenobarbital on bilirubin excretion was studied in rats with different capacities for bilirubin conjugation. Drug treatment induced substantial increases in bilirubin UDP-glucuronyl transferase activity in the liver of both normal and heterozygous Gunn rats, but not homozygous Gunn rats in which enzyme activity is completely absent. However, enhancement of bilirubin excretion in vivo was observed only in heterozygous Gunn rats. In these animals the maximum capacity to excrete bilirubin into bile ( $T_{\max }$ ), like the activity of the conjugating enzyme, was half normal; phenobarbital caused an increase in $T_{\max }$ to levels characteristic of normal animals, with a twofold rise in the excretion of conjugated pigment. This appeared to be largely unrelated to enhancement of bile flow, and there was no stimulation of alternate pathways of bilirubin excretion.

Conjugated bilirubin was consistently recovered from the plasma and urine of both untreated normal and heterozygous Gunn rats infused with unconjugated pigment. The quantities thus recovered comprised a similar fraction of the total pigment conjugated in both types of animal. Moreover, there were linear correlations between $T_{\max }$ and both the rate of bile flow and the activity of the conjugating enzyme over the range of values represented by control rats of both types. These findings suggest that the process by which conjugated bilirubin is secreted into the bile is closely related to conjugation and limits the final excretory rate at different levels of pigment excretion. The phenobarbital effect uniquely

Presented in part at the Annual Meeting of the American Federation for Clinical Research, Atlantic City, N. J., May 1968 (1).

Dr. Robinson is the recipient of Career Development Award AM 19600 from the U. S. Public Health Service. Dr. Nagasawa's present address in Second Department of Internal Medicine, Nagoya City Hospital Medical School, Nagoya, Japan.

Received for publication 12 December 1970 and in revised form 2 July 1971. observed in heterozygous Gunn rats appears to be mediated primarily by enhancement of the limited capacity for bilirubin conjugation with an associated rise in functional secretory capacity.

\section{INTRODUCTION}

Phenobarbital lowers serum bilirubin concentration in some patients with jaundice and is currently being evaluated as a therapeutic agent for hyperbilirubinemia (2-4). However, the mechanism of the phenobarbital effect is incompletely understood, partly because of our still rudimentary knowledge of the normal pathways of bilirubin excretion. Preliminary experiments from this laboratory (5), like a few previous studies $(2,4,6)$, suggested that the primary action of phenobarbital in vivo is to augment pigment conjugation. Other reports have emphasized effects of drug treatment on different aspects of hepatic excretory function (7-10). Systematic investigations of the patterns of bile pigment excretion and the alterations induced by phenobarbital were therefore undertaken in normal rats and both homozygous and heterozygous Gunn rats, mutant animals with, respectively, complete and partial impairment of pigment conjugation (11-13).

\section{METHODS}

Male rats ${ }^{1}$ weighing $350-480$ g were studied. Experimental animals received subcutaneous injections of phenobarbital, ${ }^{2}$ $40-100 \mathrm{mg} / \mathrm{kg}$ per day 6 days of each week, and controls received comparable injections of drug solvent; similar dose ranges were used for each type of rat studied. Investigations

\footnotetext{
${ }^{1}$ Although Gunn rats are of the Wistar strain, SpragueDawley rats (Charles River Breeding Labs., Inc., Wilmington, Mass.) were used as normals for reasons of convenience. Bilirubin glucuronyl transferase activity in liver of the latter animals is similar to that in normal Wistar rats (Table II) ; maximum bilirubin excretion (Table $\mathrm{I}$ ) is also comparable with that reported for normal Wistar animals (14).

${ }^{2}$ Sodium phenobarbital injection; William S. Merrell Co., Cincinnati, Ohio.
} 
were performed after 4-5 wk of treatment, the time needed to achieve maximal drug effect in the human subject studied by Crigler and Gold (3). In each set of experiments four to six animals from different experimental groups were intermixed and studied simultaneously.

Excretion of a tracer dose of labeled bilirubin. Rats were anesthetized with ether, and the common bile duct was cannulated with polyethylene tubing. ${ }^{3}$ A catheter was also inserted into a lateral tail vein for infusion of physiological saline at a rate of $1 \mathrm{ml} / \mathrm{hr}$. The animals recovered from anesthesia within $\frac{1}{2} \mathrm{hr} .2-3 \mathrm{hr}$ after surgery most of the rats received $0.1-0.2 \mu \mathrm{Ci}(10-20 \mu \mathrm{g})$ bilirubin- ${ }^{14} \mathrm{C}^{4}$ dissolved in normal rat serum (15) as a single pulse through the tail vein catheter. Others were given $0.3-0.4 \mu \mathrm{Ci}(10-13 \mu \mathrm{g})$ bilirubin- ${ }^{3} \mathrm{H},{ }^{5}$ because bilirubin $-{ }^{14} \mathrm{C}$ was to be included in a subsequent pigment infusion. Bile samples were collected on ice and in darkness at $15,30,60,120,180$, and $240 \mathrm{~min}$. Additional samples were collected at 7 and $22 \mathrm{hr}$ in the experiments with homozygous Gunn rats. The volume of each sample was recorded, and a measured quantity was counted in a liquid scintillation spectrometer $(16) ;{ }^{\circ}$ counting efficiency was determined by automatic external standardization with a ${ }^{133} \mathrm{Ba}$ source. In several experiments the remaining portions of bile were pooled, and the fraction of the total radioactivity present as labeled bilirubin was determined by crystallization (19); nonradioactive rat bile containing a measured quantity of bilirubin was added to the bile from homozygous Gunn rats.

Maximum capacity for bilirubin excretion. This was measured the day after the tracer study, i.e., $24 \mathrm{hr}$ after surgery. Unconjugated bilirubin ${ }^{7}$ in isotonic solution (20) was administered by continuous infusion through the tail vein catheter at a rate of $90-120 \mu \mathrm{g} / \mathrm{min}$ per $100 \mathrm{~g}$ body weight. Bile samples were collected in small graduated tubes at 10 to 15 -min intervals for $60 \mathrm{~min}$, the duration of infusion. The volume was measured, and the sample was diluted with water for determination of bilirubin concentration (21). The maximum rate of pigment excretion $\left(\mathrm{T}_{\max }\right)$ was generally reached $20-30 \mathrm{~min}$ after beginning the infusion, and the mean of all subsequent values was calculated for each animal.

All experiments were performed under identical conditions. Although not monitored routinely, rectal temperatures in 10 rats ranged from 35.1 to $36.7^{\circ} \mathrm{C}$. This mild hypothermia may have led to a small reduction in $\mathrm{T}_{\max }$ and bile flow (22), but the same ranges of temperature were observed in all types of rat studied. Moreover, the findings in normal control rats were similar to those reported in earlier studies $(14,20)$.

Several animals were sacrificed at the end of the infusion. Blood was removed from the vena cava for measurement of the concentrations of conjugated and unconjugated bilirubin in serum (23). Conjugated bilirubin was also assayed (24) in urine collected during the infusion combined with that recovered from the bladder at autopsy. The liver was perfused with cold saline, and total and conjugated bilirubin concentrations were measured by the method of Hargreaves

\footnotetext{
${ }^{3}$ Intramedic PE 50; Clay-Adams, Inc., New York.

" Prepared in rats by the method of Ostrow, Hammaker, and Schmid (16), as modified by Barrett, Mullins, and Berlin (17).

${ }^{5}$ Prepared by the method of Lester and Klein (18).

- Model Mark I; Nuclear-Chicago Corporation, Des Plaines, Ill.

${ }^{7}$ Pfanstiehl Labs., Inc., Waukegan, Ill.
}

(25).$^{8}$ In all of these animals the infusion dose had been adjusted to $120 \mu \mathrm{g}$ bilirubin/min per $100 \mathrm{~g}$ to permit comparisons of pigment distribution.

To determine whether there was excretion of labeled nonbilirubin products, $0.5-0.7 \mu \mathrm{Ci}(50-70 \mu \mathrm{g})$ bilirubin $-{ }^{14} \mathrm{C}^{4}$ was incorporated into the infusion in several of the experiments. Total disintegrations per minute per microgram bilirubin present in $T_{\max }$ bile were compared with the corresponding value for the infusion dose; values were derived from raw disintegrations per minute per milliliter and micrograms bilirubin per milliliter in these media. Since the rate of maximum bilirubin excretion greatly exceeded that of basal pigment output, $\mathrm{T}_{\max }$ bile was only slightly diluted by unlabeled endogenous pigment.

Chromatographic analysis of bile pigments. The diazo derivatives of conjugated and unconjugated bilirubin were separated after reaction of the bile with 2,4-dichloroaniline, as described in a recent publication (26). Bands were eluted with methanol, and the optical densities at $540 \mathrm{~m} \mu$ were measured. This method has proved highly reproducible; values for either the conjugated or the unconjugated pigment did not differ by more than $4 \%$ with portions of the same bile sample assayed on four separate occasions. Recovery of total chromatographed pigments averaged $76.3 \%$ in four experiments with rat bile (predominantly conjugated bilirubin) and $82.6 \%$ in six experiments with unconjugated bilirubin, reflecting an approximately proportionate loss of both the conjugated and unconjugated pigments.

Capacity of the liver to conjugate bilirubin in vitro. Measurements were usually from animals sacrificed 1 day after the bilirubin infusion, when bile bilirubin excretion had returned to near-normal levels in all but the homozygous Gunn rats. Similar results were obtained in all three types of rat when sacrificed directly without previous surgery or pigment infusion. Bilirubin UDP-glucuronyl transferase activity was assayed by the method of Van Roy and Heirwegh (24), as modified by Black and Billing (27). Liver protein was measured by the method of Lowry, Rosebrough, Farr, and Randall (28), using human albumin ${ }^{\circ}$ as a standard.

\section{RESULTS}

No relationship was observed between any of the experimental findings and the dosage of phenobarbital. Individual dosage rates will therefore not be specified.

Excretion of a tracer dose of labeled bilirubin. Findings were comparable with either ${ }^{14} \mathrm{C}$ - or ${ }^{8} \mathrm{H}$-labeled bilirubin. Biliary excretion of the tracer was similar in heterozygous Gunn rats and normal rats and was unaffected by treatment with phenobarbital in both types of animal (Fig. 1). Label was excreted much more slowly in homozygous Gunn rats, but again the curves for treated and control animals were virtually superimposable. Measurements of the per cent of the excreted radioactivity present in labeled bilirubin were performed

\footnotetext{
${ }^{8}$ The accuracy of this technique was evaluated with liver from two mice which $5 \mathrm{~min}$ earlier had received $1.5 \times 10^{5}$ $\mathrm{dpm}(0.35 \mathrm{mg})$ bilirubin $-{ }^{14} \mathrm{C}$ intravenously; values for total bilirubin concentration according to the Hargreaves method were 98 and $108 \%$ of those obtained by radioassay. In addition, the assay for conjugated bilirubin was not affected by additions of unconjugated pigment to liver homogenates.

' Sigma Chemical Co., St. Louis, Mo.
} 


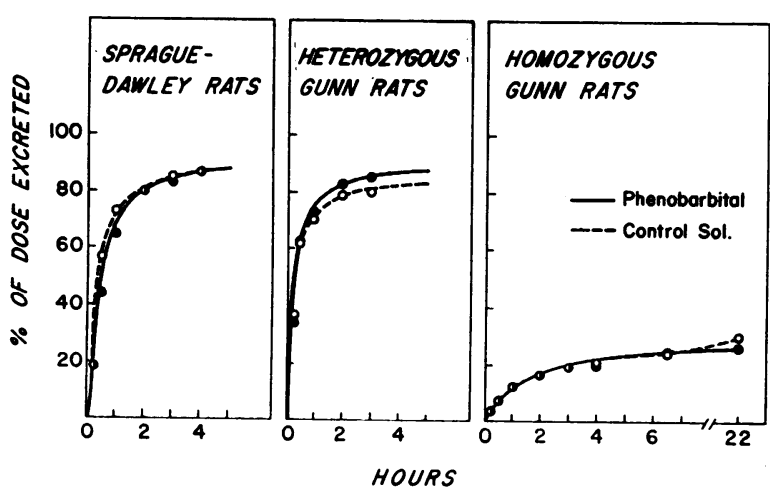

FIgURE 1 Cumulative excretion of radioactivity in bile after injection of a tracer dose of labeled bilirubin. Each point represents the mean of four to six observations. SE are not shown because of consistent overlap between values for control and drug-treated animals. Per cent of total bile radioactivity present in labeled bilirubin was similar in control and drug-treated animals of each type.

in one to three animals from each treatment and control group. These were discontinued when it became evident that the results overlapped in corresponding treated and control animals. Similar values, falling between 71 and $88 \%$, ${ }^{10}$ were observed for both normal and heterozygous Gunn rats; these are comparable with previous findings for normal animals (19). As anticipated (19), a much smaller fraction of the total bile radioactivity (8-25\%) was recovered in bilirubin with homozygous Gunn rats, either control or drug-treated.

${ }^{10}$ These values may be misleadingly low because of some degradation of labeled pigment during preparation or analysis. Crystallization (15) of some of the injection solution in one experiment revealed that only $78 \%$ of the dose radioactivity was recoverable as bilirubin.
Maximum capacity for bilirubin excretion (Table I). Phenobarbital failed to alter $\mathrm{T}_{\max }$ in the normal rats. There was also no enhancement of the comparatively negligible capacity of homozygous Gunn rats to excrete a bilirubin load. By contrast, a significant drug effect was observed in heterozygous Gunn rats, in which $T_{\max }$ rose from half normal to levels similar to those of normal animals.

Drug treatment was associated with an increase in bile flow in heterozygous Gunn rats. An apparently similar change in homozygous Gunn rats was not statistically significant according to the $t$ test (29). The small rise in bile flow in the Sprague-Dawley rats was also not statistically significant. The concentration of bilirubin in bile remained approximately the same after drug treatment in Sprague-Dawley and homozygous Gunn rats, but increased with phenobarbital therapy in heterozygous Gunn rats as a consequence of the proportionately greater enhancement of pigment excretion than of bile flow.

When values for individual animals were considered, there was a linear relationship between $T_{\max }$ and bile flow over the range observed in both control heterozygous Gunn rats and control Sprague-Dawley rats (Fig. 2 ); the correlation coefficient (29) was 0.89 . (Correlation coefficients were 0.95 and 0.83 , respectively, if separate regression lines were calculated for each of these groups.) There was greater scatter of values for the corresponding drug-treated animals, with a correlation coefficient of only 0.22 . Although the number of homozygous Gunn rats studied was small, there appeared to be a correlation between bile flow and the low levels of maximum pigment excretion in these animals whether or not phenobarbital had been given; however,

TABLE I

Maximum Bilirubin Excretion in Bile in Normal Rats and Homorygous and Heterozygous Gunn Rats Treated with Phenobarbital

\begin{tabular}{|c|c|c|c|c|c|}
\hline \multirow[b]{2}{*}{ Animal type } & \multirow[b]{2}{*}{ Treatment } & \multirow[b]{2}{*}{ No. } & \multicolumn{3}{|c|}{ Maximum bilirubin excretion } \\
\hline & & & $\mathrm{T}_{\max } *$ & $\begin{array}{l}\text { Average } \\
\text { bile flow }\end{array}$ & $\begin{array}{l}\text { Bile bilirubin } \\
\text { concentration }\end{array}$ \\
\hline & & & $\begin{array}{c}\mu \mathrm{g} / \min \text { per } \\
100 \mathrm{~g}\end{array}$ & $\begin{array}{c}\mu l / \min \text { per } \\
100 \mathrm{~g}\end{array}$ & $\mu g / \mu l$ \\
\hline Sprague-Dawley & Control & 9 & $60.4 \pm 3.9$ & $5.9 \pm 0.5$ & $9.7 \pm 1.3$ \\
\hline Sprague-Dawley & Phenobarbital & 8 & $60.8 \pm 3.9$ & $6.5 \pm 0.8$ & $10.2 \pm 1.2$ \\
\hline Homozygous Gunn & Control & 4 & $0.3 \pm 0.1$ & $3.9 \pm 1.4$ & $0.07 \pm 0.01$ \\
\hline Homozygous Gunn & Phenobarbital & 5 & $0.4 \pm 0.1$ & $5.9 \pm 0.8$ & $0.07 \pm 0.01$ \\
\hline Heterozygous Gunn & Control & 10 & $\begin{array}{c}30.3 \pm 2.9 \\
(<0.001)\end{array}$ & $\begin{array}{l}4.0 \pm 0.3 \\
(<0.005)\end{array}$ & $\begin{array}{c}7.5 \pm 0.3 \\
(<0.05)\end{array}$ \\
\hline Heterozygous Gunn & Phenobarbital & 7 & $57.6 \pm 2.6$ & $6.4 \pm 0.7$ & $9.7 \pm 1.0$ \\
\hline
\end{tabular}

Mean values \pm SE (29) are shown. $P$ values from $t$ tests (29) are shown between pairs of corresponding measurements. These are not shown if $P>0.05$.

* Refers to $\mu \mathrm{g}$ total bilirubin. See text for fraction conjugated. 
this could be substantiated statistically for only the treated homozygotes (correlation coefficient 0.97), but not the controls (coefficient 0.46 ).

The experiments with bilirubin- ${ }^{14} \mathrm{C}$ indicated that, except in homozygous Gunn rats, the infused pigment was excreted intact without degradation to radioactive catabolites. In six untreated heterozygous rats the ratio of raw disintegrations per minute per microgram bilirubin in bile vs. that in the infusion was 0.95 (SE 0.09), compared with 0.98 (SE 0.14) in four treated animals. Values for three control and two treated Sprague-Dawley rats overlapped and were similar to those for heterozygous Gunn rats, ranging from 0.87 to 1.14 . On the other hand, ratios of 1.5 and 1.6, respectively, were found for one control and one treated homozygous Gunn rat.

Conjugated bilirubin was found in the serum of each of the six control Sprague-Dawley rats and the four control heterozygous Gunn rats in which this was measured at the end of the infusion. In the normal animals the mean value for total serum bilirubin was $32.4 \mathrm{mg} /$ $100 \mathrm{ml}$ (SE 2.4), of which $22.4 \%$ (SE 1.6) was conjugated; the corresponding values for the heterozygous Gunn rats were $41.6 \mathrm{mg} / 100 \mathrm{ml}$ (SE 5.3 ) and $11.4 \%$ (SE 1.4), respectively. Conjugated hyperbilirubinemia was further confirmed by chromatographic identification (26) of the conjugated diazo derivative. Small amounts of bilirubin were found in the urine in both types of animal (Table III). Total bilirubin concentration in liver of the normal rats averaged $0.45 \mathrm{mg} / \mathrm{g}$ (SE 0.04 ), $71.1 \%$ ( $\mathrm{SE} 4.1$ ) of which was conjugated; the corresponding values for the heterozygous Gunn rats were $0.79 \mathrm{mg} / \mathrm{g}$ (SE 0.19) and $32.4 \%$ (SE 5.6).

The total amounts of conjugated bilirubin in bile, liver, serum, and urine in these animals are shown in Table III. Although the "pool size" for conjugated bilirubin in serum is difficult to assess, we have made the assumptions that the conjugate is distributed in the same volume $(30,31)$ as serum albumin, to which it is chiefly bound (32), and that there is little diffusion of this polar molecule into the tisues. An error in this assumption would not alter the finding that somewhat more than half the amount of conjugated bilirubin is found in each of these four compartments in heterozygous Gunn rats as compared with normal rats; i.e., that a similar percentage of the total conjugate is recovered in each compartment in both types of animal.

Chromatographic analysis of bile pigments. Two major bands, conforming to the diazo derivatives of conjugated and unconjugated bilirubin (26), were observed in thin-layer chromatograms prepared from the bile of normal and heterozygous Gunn rats. These accounted for virtually all of the eluted optical density. Occasionally, a faint band migrating between these two, with $R_{f}$ $0.70-0.75$, was also noted. Only the unconjugated diazo

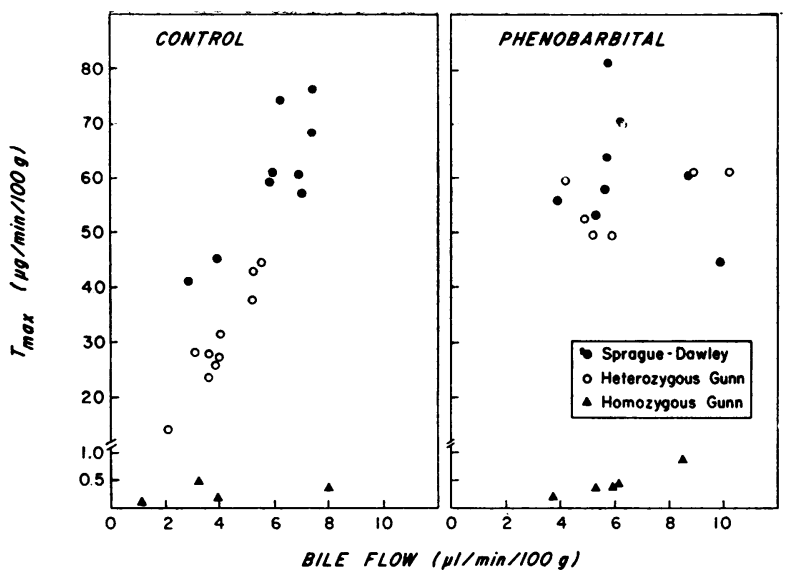

Figure 2 Comparison of maximum bilirubin excretion in bile $\left(T_{\max }\right)$ and the rate of bile flow in individual rats. There was a significant linear correlation between these values in control heterozygous Gunn and Sprague-Dawley rats, but not in drug-treated animals (see text).

derivative was found in bile from homozygous Gunn rats. The findings were not significantly altered by phenobarbital in all three types of animal. In $\mathrm{T}_{\max }$ bile from normal control rats, the conjugated diazo product accounted for a mean of $80.2 \%$ (SE 6.8) of the eluted optical density as compared with $84.0 \%$ (SE 1.8 ) for the treated animals. Values were slightly lower for heterozygous Gunn rats, ${ }^{11}$ but again were comparable in control and treated animals: $70.3 \%$ (SE 2.1) and $74.0 \%$ (SE 1.7), respectively. Thus, the rise in $\mathrm{T}_{\max }$ in heterozygous Gunn rats (Table I) was associated with a proportionate increase in the excretion of conjugated pigment.

These values indicate that $20-30 \%$ of the diazo pigment derived from $T_{\max }$ bile is unconjugated. Still higher figures have been reported by Van Roy and Heirwegh (24), who used different diazotization and chromatographic techniques. These findings would be most readily explained by the presence of large amounts of conjugated pigment I, which on diazotization yields equal quantities of the conjugated and unconjugated derivative $(26,33)$. Preliminary experiments with a chromatographic system which separates the native bile pigments (26) are consistent with this supposition.

Capacity of the liver to conjugate bilirubin in vitro (Table II). In all three groups of animals phenobarbital treatment led to an absolute increase in liver weight; however, there was little or no change in relative liver weight in the normal animals. Drug treatment induced an increase in liver protein concentration in the two groups tested.

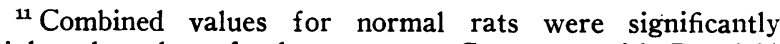
higher than those for heterozygous Gunn rats with $P<0.01$ by $t$ test (29). 
TABLE II

Bilirubin Conjugation In Vitro in Normal, Homozygous, and Heterozygous Gunn Rats Treated with Phenobarbital

\begin{tabular}{|c|c|c|c|c|c|c|c|c|}
\hline Animal type & Treatment & No. & Liver & eight & Liver protein & $\begin{array}{l}\text { Biliru } \\
\text { activi }\end{array}$ & $\begin{array}{l}\text { in glucuronyl } \\
\text { y: conj. biliru }\end{array}$ & $\begin{array}{l}\text { ansferase } \\
\text { n formed }\end{array}$ \\
\hline Sprague-Dawley & Control & 10 & $\begin{array}{c}g \\
14.0 \pm 0.7 \\
(<0.001)\end{array}$ & $\begin{array}{c}g / 100 \mathrm{~g} \\
\text { body wt } \\
3.9 \pm 0.2\end{array}$ & $\begin{array}{c}m g / g \\
184.8 \pm 8.0 \\
(<0.01)\end{array}$ & $\begin{array}{l}m g / h r \text { per } \\
\text { g liver } \\
1.6 \pm 0.1 \ddagger \\
(<0.001)\end{array}$ & $\begin{array}{l}m g / h r \text { per } \\
g \text { protein } \\
8.3 \pm 1.2 \\
(<0.01)\end{array}$ & $\begin{array}{c}\mu g / \min \text { per } \\
100 \mathrm{~g} \text { body } w t \\
101.3 \pm 10.8 \\
(<0.001)\end{array}$ \\
\hline Sprague-Dawley & Phenobarbital & 8 & $19.8 \pm 0.7$ & $4.2 \pm 0.2$ & $215.0 \pm 14.0$ & $3.2 \pm 0.2$ & $14.4 \pm 1.3$ & $222.3 \pm 22.7$ \\
\hline Homozygous Gunn & Control & 5 & $\begin{array}{c}11.0 \pm 0.6 \\
(<0.05)\end{array}$ & $\begin{array}{r}3.1 \pm 0.1 \\
(<0.05)\end{array}$ & 一 & 0 & 0 & 0 \\
\hline Homozygous Gunn & Phenobarbital & 3 & $14.8 \pm 0.9$ & $4.1 \pm 0.4$ & - & 0 & 0 & 0 \\
\hline Heterozygous Gunn & Control & 6 & $\begin{array}{c}11.2 \pm 1.2 \\
(<0.01)\end{array}$ & $\begin{array}{l}2.9 \pm 0.3 \\
(<0.025)\end{array}$ & $\begin{array}{c}167.0 \pm 11.0 \\
(<0.05)\end{array}$ & $\begin{array}{l}0.8 \pm 0.2 \\
(<0.001)\end{array}$ & $\begin{array}{c}4.7 \pm 0.9 \\
(<0.001)\end{array}$ & $\begin{array}{c}36.0 \pm 6.1 \\
(<0.001)\end{array}$ \\
\hline Heterozygous Gunn & Phenobarbital & 8 & $17.1 \pm 1.1$ & $4.0 \pm 0.2$ & $199.0 \pm 8.2$ & $2.0 \pm 0.1$ & $9.5 \pm 0.5$ & $131.6 \pm 7.8$ \\
\hline
\end{tabular}

Mean values $\pm \mathrm{SE}$ are shown. $P$ values are shown in parentheses if $P<0.05$.

* Calculated on the basis of liver weight as \% body weight.

$\ddagger$ Corresponding value for 10 normal Wistar rats is $1.4 \pm 0.1$.

Bilirubin UDP-glucuronyl transferase activity was undetectable in liver from homozygous Gunn rats, either control or drug-treated. Values in control heterozygous Gunn rats were approximately half those in the normal controls. Phenobarbital caused a significant rise in transferase activity in both of these groups, and the values for heterozygous Gunn rats now exceeded normal control levels $(P<0.05$ by $t$ test [29]).

$T_{\max }$ is plotted against glucuronyl transferase activity in individual animals in Fig. 3. There was a linear correlation for the values from both control heterozygous

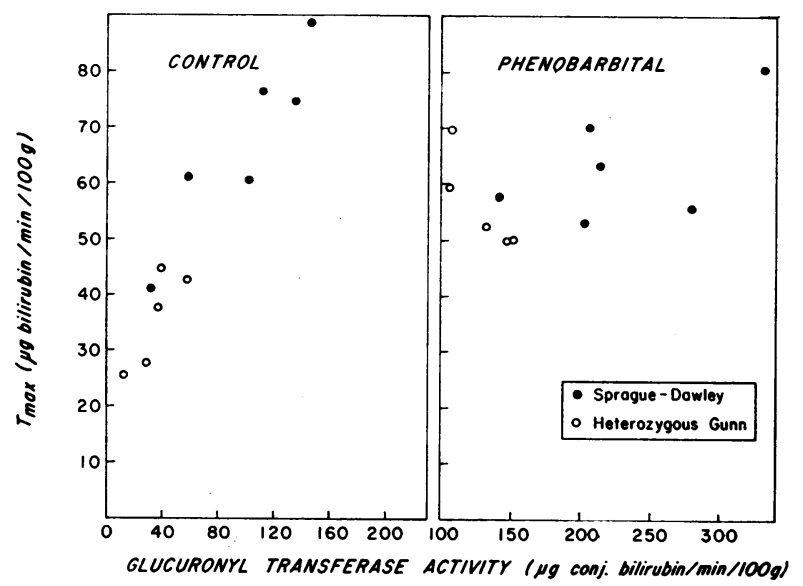

FIGURE 3 Comparison of maximum bilirubin excretion in bile $\left(T_{\max }\right)$ and bilirubin UDP-glucuronyl transferase activity in liver in individual rats. Enzyme activity is expressed in the same units as bilirubin excretion, except that the latter includes both conjugated and unconjugated pigment. There was a significant linear correlation for control heterozygous Gunn and Sprague-Dawley rats, but not for drug-treated animals (see text). Values for homozygous Gunn rats are not shown since enzyme activity was uniformly undetectable.
Gunn rats and control Sprague-Dawley animals, with a correlation coefficient of 0.95 . (Correlations are 0.82 and 0.93 , respectively, if the two groups are considered separately.) Correlation was random (coefficient 0.44 ) for phenobarbital-treated animals, presumably because $\mathrm{T}_{\max }$ is limited (Table $\mathrm{I}$ ), whereas transferase activity is stimulated more freely (Table II).

\section{DISCUSSION}

Phenobarbital has manifold effects upon liver metabolism (34), and the precise manner in which it can facilitate bilirubin excretion may well be complex. Since barbiturates augment the activity of bilirubin UDP-glucuronyl transferase $(6,8,34-36)$ but apparently do not affect jaundice when this enzyme is completely absent $(4,6)$, induction of enzyme activity seemed the primary mode of drug action. However, this fails to explain why marked increases in the capacity to conjugate bilirubin in vitro, as with drug-treated Sprague-Dawley rats (Table II), are not necessarily associated with facilitated pigment excretion in vivo (Fig. 1, Table I). Other lines of investigation have suggested the importance of increased rates of bile flow and anion secretion $(7,9)$, enhanced hepatic uptake (10), and enlarged liver mass (7). A final consideration is that phenobarbital might stimulate the alternate pathways by which subjects with impaired conjugation may excrete bile pigment (19).

In the present experiments phenobarbital had no effect on the rate of basal pigment excretion, as assessed with tracer doses of labeled bilirubin (Fig. 1). Indeed, the similar findings in normal and heterozygous Gunn rats, both control and drug-treated, indicate that this function in rats is not influenced by widely divergent levels of bilirubin glucuronyl transferase activity; only when enzyme activity is completely deficient, in homozygous 
Gunn rats, is the excretion of labeled bilirubin compromised. Similarly, Black and Billing found marked depressions of enzyme activity but only minimal hyperbilirubinemia in some patients with Gilbert's syndrome, suggesting that the liver has a large reserve capacity for pigment conjugation (27).

On the other hand, the studies of maximal bilirubin excretion $\left(T_{\max }\right)$ revealed a number of intriguing relationships. Interpretation must take into acount the striking enhancement of $T_{\max }$ in heterozygous Gunn rats but the lack of effect in normal rats, despite substantial increases in conjugating activity in both types of animal (Tables I and II). It must consider the significance of the conjugated hyperbilirubinemia and bilirubinuria in untreated heterozygous Gunn rats undergoing infusions of unconjugated pigment in light of the compromised capacity of these animals to form the conjugated product. Finally, it should explain the correlations between $\mathrm{T}_{\max }$ and both the rate of bile flow and the activity of the conjugating enzyme in control, but not drug-treated, heterozygous Gunn rats and normal animals (Figs. 2 and 3). These findings seem best explained by an effect of phenobarbital on two apparently interrelated steps in the excretory pathway, conjugation and biliary secretion of the conjugated pigment.

Only in heterozygous Gunn rats did phenobarbital lead to augmented bilirubin excretion in vivo, and there can be little doubt that enhanced conjugation played a major role. In view of the gene-dose relationship, it is not surprising that bilirubin UDP-glucuronyl transferase activity in the liver of these animals before treatment is half normal (Table II). Similarly, the $T_{\max }$ for bilirubin is half that of normal animals (Table $\mathrm{I}$ ). This relationship might indicate that the partial impairment of conjugation in heterozygous Gunn rats is rate limiting in the presence of a bilirubin load, or that another step is limiting but is linked to the conjugation process. The consistent recovery of conjugated bilirubin in plasma and urine of untreated heterozygous Gunn rats supports the latter conclusion. Other investigators have reported conjugated hyperbilirubinemia in normal subjects with increased bilirubin excretion (37-39), and have interpreted this to indicate that a step distal to conjugation, i.e. secretion, is rate limiting under these conditions. The present findings in heterozygous Gunn rats suggest that this is also true at decreased levels of pigment conjugation. Moreover, at the two different levels of excretory capacity represented by these and by normal rats, a fixed percentage of the total pigment conjugated appears to be accommodated by the mechanism for biliary secretion, while a more or less fixed percentage is lost into the plasma and urine (Table III).

The relationships between $T_{\max }$ and both the rate of bile flow and the activity of the conjugating enzyme
TABLE III

Distribution of Conjugated Bilirubin in Normal Rats and Heterozygous Gunn Rats Given 60-min Infusions of Unconjugated Bilirubin

\begin{tabular}{|c|c|c|c|c|}
\hline \multirow{3}{*}{ Tissue } & \multicolumn{4}{|c|}{ Recovery of conjugated bilirubin } \\
\hline & \multicolumn{2}{|c|}{$\begin{array}{l}\text { Sprague-Dawley } \\
\text { rats }(6)\end{array}$} & \multicolumn{2}{|c|}{$\begin{array}{l}\text { Heterozygous Gunn } \\
\text { rats (4) }\end{array}$} \\
\hline & $\begin{array}{l}m g / 100 g \\
\text { body wt }\end{array}$ & $\begin{array}{l}\% \text { of } \\
\text { total* }\end{array}$ & $\begin{array}{l}m g / 100 g \\
\text { body wt }\end{array}$ & $\begin{array}{l}\text { \% of } \\
\text { total* }\end{array}$ \\
\hline Bile $\ddagger$ & $2.1 \pm 0.2$ & $58.9 \pm 5.0$ & $1.2 \pm 0.04$ & $57.5 \pm 2.0$ \\
\hline Liver & $0.9 \pm 0.1$ & $23.8 \pm 3.1$ & $0.5 \pm 0.1$ & $25.2 \pm 2.5$ \\
\hline Plasmaई & $0.5 \pm 0.07$ & $14.7 \pm 1.8$ & $0.3 \pm 0.05$ & $16.3 \pm 2.2$ \\
\hline Urine & $0.1 \pm 0.05$ & $2.7 \pm 1.3$ & $0.03 \pm 0.01$ & $1.4 \pm 0.5$ \\
\hline Total recovery $\|$ & $3.6 \pm 0.1$ & & $2.0 \pm 0.1$ & \\
\hline
\end{tabular}

Mean values \pm SE are shown.

* Computed from fractional distribution of conjugated bilirubin in individual animals.

‡ Based on total biliary excretion of bilirubin from beginning to end of infusion $X$ percentage conjugated pigment determined by thin-layer chromatography of diazotized bile.

\$ Assumes that conjugated bilirubin is distributed in 2.5 times plasma volume (see Results).

II Corresponding values based on assay of bilirubin UDP-glucuronyl transferase activity are $4.7 \pm 0.1$ and $2.0 \pm 0.5 \mathrm{mg}$ conjugated bilirubin formed/hr per $100 \mathrm{~g}$ body weight, respectively:

(Figs. 2 and 3) add support to this concept. Since the secretory mechanism appears to govern the $T_{\max }$ for bilirubin in normal subjects (37-39), and since biliary secretion of various anions is also one of the factors determining bile flow $(40,41)$, the correlation between $\mathrm{T}_{\max }$ and bile flow in normal rats is not unexpected. That this relationship extends to heterozygous Gunn rats suggests that secretion has a regulatory role in these animals as well. If secretion is indeed rate limiting, then the correlation between $T_{\max }$ and the activity of the conjugating enzyme in both normal control rats and heterozygous Gunn rats implies an intimate association between bilirubin conjugation and secretion at the different levels represented by both types of animal. ${ }^{12}$ The studies of Hargreaves and Lathe with "cholephilic" agents also suggest that these are interrelated processes (42). This concept may seem contrary to the report that homozygous Gunn rats, which are completely unable to conjugate bilirubin, excrete an exogenous load of conjugated bilirubin normally (14). Interpretation of this finding is complicated by the fact that bile had to be used as the vehicle for the conjugated pigment (43). However, it seems probable that the secretory apparatus is intact in animals with impaired conjugation, but that its utilization may normally be a function of the rate of

\footnotetext{
12 Measurements of conjugation in vitro can be used to assess relative magnitudes of enzyme activity, but may not accurately reflect the capacity for conjugation in vivo. Nevertheless, results of the enzyme assay agreed reasonably well with total recovery of conjugated bilirubin in intact rats undergoing infusions of unconjugated pigment (Table III).
} 
ongoing conjugation within the liver cell. Such a relationship could be explained by anatomic continuity between those portions of endoplasmic reticulum concerned with pigment conjugation and the mechanism for bilirubin transport on the canalicular membrane.

In view of these relationships, it seems likely that phenobarbital enhances $T_{\max }$ in heterozygous Gunn rats by stimulation of the limited activity of bilirubin glucuronyl transferase associated with amplification of functional secretory capacity. Since $T_{\max }$ did not exceed physiologic levels in either the heterozygous Gunn rats or the normal animals (Table I), whereas glucuronyl transferase activity was stimulated to supranormal values in accordance with the type of animal studied (Table II), there appears to be an upper limit to the secretory capacity that is not shared by the conjugating mechanism. Thus, the high levels of enzyme activity induced by phenobarbital lead eventually to some dissociation between these two processes (Fig. 3).

Other effects of phenobarbital may also have played a role in the changes observed in these experiments. The hepatic uptake process, for example, was not specifically examined. On the other hand, enhancement of bile flow was insufficient to account for the increase in $T_{\max }$ in heterozygous Gunn rats, in view of the elevated concentration of bilirubin in bile (Table I) and the poor correlation between $T_{\max }$ and bile flow in individual drugtreated rats (Fig. 2). Roberts and Plaa found slight rises in $T_{\max }$ associated with increased rates of bile flow in normal rats treated with phenobarbital (7). It is not clear why average bile flow increased so little in normal rats in the present experiments; however, the highest flows in individual rats were not associated with proportionately high rates of pigment excretion (Fig. 2).

Finally, these experiments indicate that phenobarbital does not stimulate the alternate pathways by which bilirubin may be degraded to products not requiring conjugation for excretion (19). Homozygous Gunn rats rely almost entirely on these pathways (19). Although phenobarbital does not affect the level of jaundice in these animals (6), it seemed possible that this was due to offsetting increases in both bilirubin excretion and bilirubin production from nonerythroid sources (44). However, phenobarbital failed to increase the excretion of radioactivity into the bile in homozygous Gunn rats given tracer doses of labeled bilirubin (Fig. 1). Similarly, it did not affect the fraction of the total bile radioactivity present as bilirubin in these animals, in heterozygous Gunn rats, or in normal animals. Additional studies (45) have shown that phenobarbital fails to alter the rate of total pigment turnover and only mildly increases the production of early labeled bilirubin in homozygous Gunn rats, in contrast with the marked stimulation reported for normal animals (44).
Some of the present data are complex and may be subject to different interpretations. In addition, barbiturates may affect several facets of hepatic excretory function. However, all of the findings in heterozygous Gunn rats can be explained by a predominant effect on two intimately linked steps: bilirubin conjugation and the associated process by which the conjugated pigment is then excreted into the bile.

\section{ACKNOWLEDGMENTS}

The authors are grateful to Linda Lavidor and Maria Tsong for expert technical assistance and to Professor W. M. Rand of the Massachusetts Institute of Technology for advice regarding statistical analysis.

This work was supported in part by Grant AM 09834 from the U. S. Public Health Service.

\section{REFERENCES}

1. Robinson, S. H. 1969. Phenobarbital-induced rise in bilirubin conjugation in vivo. Clin. Res. 17: 309. (Abstr.)

2. Yaffe, S. J., G. Levy, T. Matsuzawa, and T. Baliah. 1966. Enhancement of glucuronide-conjugating capacity in a hyperbilirubinemic infant due to apparent enzyme induction by phenobarbital. N. Engl. J. Med. 275: 1461.

3. Crigler, J. F., Jr., and N. I. Gold. 1969. Effect of sodium phenobarbital on bilirubin metabolism in an infant with congenital, nonhemolytic, unconjugated hyperbilirubinemia, and kernicterus. J. Clin. Invest. 48: 42.

4. Arias, I. M., L. M. Gartner, M. Cohen, J. Ben Ezzer, and A. J. Levi. 1969. Chronic nonhemolytic unconjugated hyperbilirubinemia with glucuronyl transferase deficiency. Clinical, biochemical, pharmacologic and genetic evidence for heterogeneity. Amer. J. Med. 47: 395.

5. Robinson, S. H. 1969. Increased bilirubin conjugation in heterozygous Gunn rats treated with phenobarbital. Nature (London). 222: 990.

6. DeLeon, A., L. M. Gartner, and I. M. Arias. 1967. The effect of phenobarbital on hyperbilirubinemia in glucuronyl transferase deficient rats. J. Lab. Clin. Med. 70: 273.

7. Roberts, R. J., and G. L. Plaa. 1967. Effect of phenobarbital on the excretion of an exogenous bilirubin load. Biochem. Pharmacol. 16: 827.

8. Catz, C., and S. J. Yaffe. 1968. Barbiturate enhancement of bilirubin conjugation and excretion in young and adult animals. Pediat. Res. 2: 361.

9. Klaassen, C. D., and G. L. Plaa. 1968. Studies on the mechanism of phenobarbital-enhanced sulfobromophthalein disappearance. J. Pharmacol. Exp. Ther. 161: 361.

10. Reyes, H., A. J. Levi, Z. Gatmaitan, and I. M. Arias. 1969. Organic anion-binding protein in rat liver: drug induction and its physiologic consequence. Proc. Nat. Acad.Sci. U.S. A. 64: 168.

11. Carbone, J. V., and G. M. Grodsky. 1957. Constitutional nonhemolytic hyperbilirubinemia in the rat: defect of bilirubin conjugation. Proc. Soc. Exp. Biol. Med. 94: 461.

12. Schmid, R., J. Axelrod, L. Hammaker, and R. L. Swarm. 1958. Congenital jaundice in rats due to a defect in glucuronide formation. J. Clin. Invest. 37: 1123. 
13. Arias, I. M. 1959. A defect in microsomal function in nonhemolytic acholuric jaundice. J. Histochem. Cytochem. $7: 250$.

14. Arias, I. M., L. Johnson, and S. Wolfson. 1961. Biliary excretion of injected conjugated and unconjugated bilirubin by normal and Gunn rats. Amer. J. Physiol. 200: 1091.

15. Robinson, S. H., M. Tsong, B. W. Brown, and R. Schmid. 1966. The sources of bile pigment in the rat: studies of the "early-labeled" fraction. J. Clin. Invest. 45: 1569.

16. Ostrow, J. D., L. Hammaker, and R. Schmid. 1961. The preparation of crystalline bilirubin-C- ${ }^{14}$. J. Clin. Invest. 40: 1442.

17. Barrett, P. V. D., F. X Mullins, and N. I. Berlin. 1966. Studies on the biosynthetic production of bilirubin${ }^{14} \mathrm{C}$ : an improved method utilizing $\delta$-aminolevulinic acid4-14C in dogs. J. Lab. Clin. Med. 68: 905.

18. Lester, R., and P. D. Klein. 1966. Biosynthesis of tritiated bilirubin and studies of its excretion in the rat. J. Lab. Clin. Med. 67: 1000.

19. Schmid, R., and L. Hammaker. 1963. Metabolism and disposition of $\mathrm{C}^{14}$-bilirubin in congenital nonhemolytic jaundice. J. Clin. Invest. 42: 1720.

20. Weinbren, K., and B. H. Billing. 1956. Hepatic clearance of bilirubin as an index of cellular function in the regenerating rat liver. Brit. J. Exp. Pathol. 37:199.

21. Malloy, H. T., and K. A. Evelyn. 1937. The determination of bilirubin with the photoelectric colorimeter. $J$. Biol. Chem. 119: 481.

22. Roberts, R. J., C. D. Klaassen, and G. L. Plaa. 1967. Maximum biliary excretion of bilirubin and sulfobromophthalein during anesthesia-induced alteration of rectal temperature. Proc. Soc. Exp. Biol. Med. 125: 313.

23. Weber, A. Ph., and L. Schalm. 1962. Quantitative separation and determination of bilirubin and conjugated bilirubin in human serum. Clin. Chim. Acta. 7: 805.

24. Van Roy, F. P., and K. P. M. Heirwegh. 1968. Determination of bilirubin glucuronide and assay of glucuronyltransferase with bilirubin as acceptor. Biochem. J. $107: 507$.

25. Hargreaves, T. 1965. The estimation of bilirubin in liver. Clin. Chim. Acto. $11: 278$

26. Rugstad, H. E., S. H. Robinson, C. Yannoni, and A. H. Tashjian, Jr. 1970. Metabolism of bilirubin by a clonal strain of rat hepatoma cells. J. Cell Biol. 47: 703.

27. Black, M., and B. H. Billing. 1969. Hepatic bilirubin UDP-glucuronyl transferase activity in liver disease and Gilbert's syndrome. N. Engl. J. Med. 280: 1266.

28. Lowry, O. H.. N. F. Rosebrough, A. L. Farr, and R. J. Randall. 1951. Protein measurement with the Folin phenol reagent. J. Biol. Chem. 193: 265.
29. Snedecor, G. W., and W. G. Cochran. 1967. 1967. Statistical Methods. Iowa State University Press, Ames, Iowa. 6th edition.

30. Campbell, R. M., D. P. Cuthbertson, C. M. Matthews, and A. S. MacFarlane. 1956. Behavior of ${ }^{16} \mathrm{C}-$ and ${ }^{181} \mathrm{I}$-labelled plasma proteins in the rat. Int. J. Appl. Radiat. Isotop. 1 : 66.

31. Dewey, W. C. 1959. Vascular-extravascular exchange of $\mathrm{I}^{182}$ plasma proteins in the rat. Amer. J. Physiol. 197: 423.

32. Fulop, M., J. Sandson, and P. Brazeau. 1965. Dialyzability, protein binding, and renal excretion of plasma conjugated bilirubin. J. Clin. Invest. 44: 666.

33. Billing, B. H., P. G. Cole, and G. H. Lathe. 1957. The excretion of bilirubin as a diglucuronide giving the direct van den Bergh reaction. Biochem. J. 65: 774.

34. Conney, A. H. 1967. Pharmacological implications of microsomal enzyme induction. Pharmacol. Rev. 19: 317.

35. Catz, C., and S. J. Yaffe. 1962. Pharmacologic modification of bilirubin conjugation in the newborn. Amer. J. Dis. Child. 104: 516.

36. Halac, E., Jr., and C. Sicignano. 1969. Re-evaluation of the influence of sex, age, pregnancy, and phenobarbital on the activity of UDP-glucuronyl transferase in rat liver. J. Lab. Clin. Med. 73: 677.

37. Tisdale, W. A., G. Klatskin, and E. D. Kinsella. 1959. The significance of the direct-reacting fraction of serum bilirubin in hemolytic jaundice. Amer. J. Med. 26: 214.

38. Schalm, L., and A. Ph. Weber. 1964. Jaundice with conjugated bilirubin in hyperhaemolysis. Acta Med. Scand. 176: 549.

39. Snyder, A. L., W. Satterlee, S. H. Robinson, and R. Schmid. 1967. Conjugated plasma bilirubin in jaundice caused by pigment overload. Nature (London). 213: 93.

40. Sperber, I. 1959. Secretion of organic anions in the formation of urine and bile. Pharmacol. Rev. 11: 109.

41. O'Maille, E. R. L., T. G. Richards, and A. H. Short. 1966. Factors determining the maximal rate of organic anion secretion by the liver and further evidence on the hepatic site of action of the hormone secretin. J. Physiol. (London). 186: 424.

42. Hargreaves, T., and G. H. Lathe. 1963. Inhibitory aspects of bile secretion. Nature (London). 200: 1172.

43. Whelan, G., and B. Combes. 1971. Depression of biliary excretion of infused bilirubin in rats and guinea pigs by bile. Amer. J. Physiol. 220: 683.

44. Schmid, R., H. S. Marver, and L. Hammaker. 1966. Enhanced formation of rapidly labeled bilirubin by phenobarbital: hepatic microsomal cytochromes as a possible source. Biochem. Biophys. Res. Commun. 24 : 319.

45. Robinson, S. H. 1971. Production and excretion of bilirubin in Gunn rats treated with phenobarbital. Proc. Soc. Exp. Biol. Med. 138 : 281. 